\title{
3D world in orthodontics: Diagnosis, planning and great challenges
}

\section{Francesca Zotti*1 \\ ${ }^{1}$ Department of Orthodontics, Dental School, University of Brescia, Italy}

Currently the importance of accurate records is broadly recognized also in orthodontic treatment plans. The diagnostic imaging takes an important part in reaching effective and steady orthodontic results.

More significant field in which imaging is actually involved is the diagnosis of particular alterations of teeth position or affections of dento-facial structures, as well as combined treatment plans.

In this scenario, the introduction of $3 \mathrm{D}$ diagnosis obtainable by CBCT technology opened the doors to new possibilities in treatment of challenging pathologies in maxillofacial complex [1-3]. Cleft palates, as well as cleido- cranial dysplasia and other syndromes involving the skull and alveolar bones, can be approached successfully thank to the feasibility to obtain 3D images that allow pre-treatment visualization with minimal errors.

In planning phase, it is crucial to evaluate every aspect of deformity in order to catch the right timing to take action. Often cranio-facial pathologies need more than one surgery during the life of patient, because of this, a correct surgery and orthodontic planning is essential.

In cleft palate syndrome, for example, young patients received many surgical operations during their life. The most important and significant moment in cleft palate is the secondary alveolar bone graft, on which the following effective orthodontic treatment is based. This phase needs to be planned and monitored in order to be as most effective as possible in grafting surgery. In order to obtain a good healing is of course needed a perfect fitting of graft in bone defect $[4,5]$. CBCT evaluation makes possible to understand perfectly the anatomy of bone defect and, where it is requested and possible, create a custom-made scaffold.

Surely, nowadays it is more difficult to do it in cleft defects because their irregular and particular anatomical characteristics, but studies are updating the challenge.

However, in other pathologies where it is needed to understand anatomic condition in order to approach with a planned surgical procedure, $\mathrm{CBCT}$ with $3 \mathrm{D}$ images is of course the best opportunity to use.

An important focus is that $3 \mathrm{D}$ images nowadays can be used also to create scaffolds useful in bone graft: this becomes very significant syndromes or in particular diseases in which orthodontic patients need to be grafted [6]. In this way, with just one radiographic examination, this means minimal $\mathrm{x}$-rays exposure in growing patients, the clinician can obtain all information requested in order to perform a correct diagnosis and an effective treatment.

$3 \mathrm{D}$ technology is not only CBCT and imaging diagnosis, but this concept is expanding its fields of application an many great aims are now yet reached.
An important goal it was the introduction of intraoral scanners giving the possibility to "take impressions" obtaining accurate steady data and sharing these in real time. From this important target it is born the great universe of CadCam technologies in orthodontics.

A crucial turning point was the introduction of digital set up and subsequently the obtained feasibility to perform digital orthodontic treatment on the software $[7,8]$. This made possible to have the great scenario of removable orthodontic aligners that have revolutionized the modern concept of orthodontics.

This meant that, from a simple and easy to obtain image, orthodontists could have a perfect preview of treatment results both for fixed therapy, both for removable. This is very important also in well explaining informed consent to our patients: the opportunity to see $3 \mathrm{D}$ reconstructions and different phases of treatment is surely an added value in order to have a really informed consent.

Of course the possibility to obtain $3 \mathrm{D}$ images allowed to ensure more accurate diagnoses and orthodontic treatment results. It is also possible to monitor constantly our results with a vision very close to real conditions. The validity of images derived by intraoral scanners and possibility to use them to take measurements are considered clinically significant and therefore recommended to perform treatment.

\section{But what about cons?}

The first difficulty in using the $3 \mathrm{D}$ intraoral scanning is the possible to share information. If we use at chair side intraoral scanners to take impression, we have to do a laboratory able to manage captured images.

The learning curve to be able to use intraoral scanners is sometimes long especially when the tool is not used frequently. Instead it is necessary to do more and more practice in order to make this instrument really effective $[9,10]$. The possibility to obtain satisfactory results depends on our capability to use the scanner, so we have to do more and more practice.

The costs could be a problem nowadays because this technology is still expensive. However, this obstacle may be reduced by a group purchase, for example, where the office organization allows it.

Many questions and challenges are sleeping in this field, but orthodontics need to open their doors to the new and to the high-tech everyday, because the success passes through these doors.

Correspondence to: Francesca Zotti, DDS, MOrth, PhD, Department of Orthodontics, Dental School, University of Brescia, Italy, E-mail: francesca. zotti@hotmail.it

Received: April 02, 2017; Accepted: April 17, 2017; Published: April 20, 2017 


\section{References}

1. Ferreira JB, Christovam IO, Alencar DS, da Motta AF, Mattos CT, Cury-Saramago AA (2017) Accuracy and reproducibility of dental measurements on tomographic digital models: A systematic review and meta-analysis. Dentomaxillofac Radiol 31: 20160455. [Crossref]

2. Dalessandri D, Laffranchi L, Tonni I, Zotti F, Piancino MG, Paganelli C, et al. (2011) Advantages of cone beam computed tomography (CBCT) in the orthodontic treatment planning of cleidocranial dysplasia patients: a case report. Head Face Med 7: 6. [Crossref]

3. Carrara CF, Ambrosio EC, Mello BZ, Jorge PK, Soares S, Machado MA, et al. (2016) Three-dimensional evaluation of surgical techniques in neonates with orofacial cleft. Ann Maxillofac Surg 6: 246-250. [Crossref]

4. Jorge PK, Gnoinski W, Vaz Laskos K, Felício Carvalho Carrara C, Gamba Garib D, Okada Ozawa T, et al. (2016) Comparison of two treatment protocols in children with unilateral complete cleft lip and palate: Tridimensional evaluation of the maxillary dental arch. J Craniomaxillofac Surg 4: 1117-1122.
5. Mello BZ, Fernandes VM, Carrara CF, Machado MA, Garib DG, et al. (2013) Evaluation of the intercanine distance in newborns with cleft lip and palate using 3D digital casts. J Appl Oral Sci 21: 437-442. [Crossref]

6. Obregon F, Vaquette C, Ivanovski S, Hutmacher DW, Bertassoni LE (2015) Threedimensional bioprinting for regenerative dentistry and craniofacial tissue engineering. J Dent Res 94: 143S-152S. [Crossref]

7. Zhang X, Zhang Y2 (2015) Tissue engineering applications of three-dimensional bioprinting. Cell Biochem Biophys 72: 777-782. [Crossref]

8. Hazeveld A, Huddleston Slater JJ, Ren Y (2014) Accuracy and reproducibility of dental replica models reconstructed by different rapid prototyping techniques. Am J Orthod Dentofacial Orthop 145: 108-115. [Crossref]

9. De Luca Canto G, Pachêco-Pereira C, Lagravere MO, Flores-Mir C, Major PW (2015) Intra-arch dimensional measurement validity of laser-scanned digital dental models compared with the original plaster models: a systematic review. Orthod Craniofac Res 18: 65-76. [Crossref]

10. Sousa MV, Vasconcelos EC, Janson G, Garib D, Pinzan A (2012) Accuracy and reproducibility of 3-dimensional digital model measurements. Am J Orthod Dentofacial Orthop 142: 269-273. [Crossref]

Copyright: $\left({ }_{0} 2017\right.$ Zotti F. This is an open-access article distributed under the terms of the Creative Commons Attribution License, which permits unrestricted use, distribution, and reproduction in any medium, provided the original author and source are credited. 